\title{
Degree Expressions at the Syntax-Semantics Interface
}

\author{
Jens Fleischhauer
}

\section{Introduction}

This paper aims at extending the Role and Reference Grammar (RRG) approach to adverbs set out in Van Valin \& LaPolla (1997) and Van Valin (2005). Apart from the work by Nuyts (1993), Ortigosa (2003), Toratani (2007) and Mora-Bustos (2009), adverbs have received comparatively little attention in RRG. Degree adverbs have not been analyzed in RRG at all and have also been given comparatively less attention in other frameworks (for different analyses embedded in a generative tradition cf. Doetjes 1997, Vecchiato 1999). In this paper, I will primarily focus on adverbially used degree expressions, as exemplified by the English examples in (1). A lot is used to indicate the intensity of frightening in (a). Following Bolinger (1972), cases like in (a) are called '(verbal) degree gradation' (I adopt the terminology put forward in Löbner 2012). In (b) a lot is used to specify the temporal duration of the sleeping event, whereas in (c) it indicates the frequency of his going to the cinema. Examples (b) and (c) are subsumed under the label 'extent gradation.'

(1) a. The dog frightens the boy a lot.

b. Last night, the boy slept a lot.

c. He goes to the cinema a lot.

Although English makes use of a single adverb for extent and degree gradation, other languages like Polish use different adverbs for both subtypes of verb gra- 
dation. In Polish, the degree expression bardzo 'very' is used for degree gradation and it makes use of $d u \dot{z} o$ 'much' for extent gradation. ${ }^{1}$

(2) a. Ta dziewczyna bardzo lubi tego psa.

DEM girl very likes DEM dog

'The girl likes the dog very much.'

b. On dużo spat.

he much slept

'He slept a lot.'

c. Ona chodzi dużo do kin-a.

she goes much PREP cinema-GEN

'She goes to the cinema a lot.'

English and Polish exemplify two different patterns in the distribution of adverbial degree expressions. In English, the same degree expression is used for extent and degree gradation and it can also be used as an adnominal quantity expression, as shown in (3). ${ }^{2}$ Polish, on the other hand, uses two different degree expressions for both subtypes of verb gradation. The one used for extent gradation - duzo - is also used adnominally to specify a nominal quantity (4). Bardzo, the degree expression used for verbal degree gradation, does not have an adnominal use but rather also functions as an intensifier of adjectives in the positive form (5). In English, a lot cannot be used for grading adjectives, instead very has to be used (as indicated in the translation of example (5)).

(3) There is a lot of chocolate in the cake.

(4) a. Ten mężczyzna ma dużo książek.

DEM man has much books.GEN

'The man has many books.'

b. W jeziorze jest dużo wod-y.

PREP lake.LOC is much water-GEN

'There is much water in the sea.'

1 List of abbreviations used in the paper: ABL 'ablative', ACC 'accusative', AOR 'aorist', AUX 'auxiliary', cAUS 'causative', COMP 'comparative', DAT 'dative', DEF 'definite', DEM 'demonstrative', DISTR 'distributive', E 'exclusive', GEN 'genitive', INCEP 'inceptive', IPFV 'imperfective', LOC 'locative', PERF 'perfective', PL 'plural', POSS 'possessive', PST 'past', PREP 'preposition', PROG 'progressive', REFL 'reflexive', REMPST 'remote past', sG 'singular'.

2 I use the term 'adnominal quantity expression' to refer to the use of degree expressions in the nominal domain. 
(5) Ten chtopiec jest bardzo wysoki.

DEM boy is very tall

'The boy is very tall.'

The contrast indicated by the English and Polish examples leads to different questions. First, is there any particular reason why degree expressions used for extent gradation (English a lot, Polish $d u \dot{z} o$ ) are also used as adnominal quantity expressions and those restricted to degree gradation (Polish bardzo and English very) are not? Second, do languages like Polish display a difference between extent and degree gradation that, as such, does not exist in, for example, English? Or is it a universal distinction between extent and degree gradation, which in English is only masked by the use of the same adverbial expression for both?

In this paper, I will present answers to both questions. The central claim will be that languages like English display the same distinction between extent and degree gradation as languages such as Polish do. Essentially, the distinction between extent and degree gradation will be related to two different syntactic configurations in which adverbially used degree expressions show up. This results in the claim that degree expressions in English and similar languages are syntactically ambiguous, whereas Polish, for example, uses two distinct and syntactically unambiguous adverbial degree expressions. In RRG terms, I will propose that extent gradation is syntactically realized at the core layer, whereas degree gradation is expressed at the nucleus layer. This syntactic difference will also explain the cross-categorical distribution of degree expressions, namely why expressions used for extent gradation also function as adnominal quantity expressions. In this paper, I will focus on data from French and German, which display the same kind of difference exemplified by the English and Polish examples above. Section 2 will provide the relevant background on verb gradation. The cross-categorical distribution of degree expression will be discussed in section 3. Section 4 provides a discussion of the French degree adverb beaucoup 'a lot' and argues that it is syntactically ambiguous. The relevant background of adverbs in RRG is introduced in section 5. Section 6 presents the crucial data on which the syntactic analysis of adverbial degree expressions in section 7 is based. The data will consist of scope interactions between degree adverbs and (aspectual) operators. In section 8 , I extend the syntactic analysis to adnominal uses of degree expressions and end with a conclusion in section 9. 


\section{Verb gradation}

Gradation is usually considered to be a prototypical property of adjectives. ${ }^{3}$ For adjectives, gradability is grammatically relevant since only gradable adjectives appear in degree constructions without coercion of their meaning. In languages that have degree morphology, such as English with its comparative - er or superlative - est, only gradable adjectives take these morphemes (6a). Although degree morphology is not universal, all languages that have gradable adjectives also have special degree constructions (Bhat \& Pustet 2000) such as the equative (6b) or the combination of the adjective with a degree expression like English very (c).

(6) a. tall - taller - tallest; dead - \#deader - \#deadest

b. He is as tall as his brother.

c. He is very tall.

As argued quite early by Sapir (1944) and embedded in a broader discussion by Bolinger (1972), gradation is not restricted to adjectives, but a characteristic of all word classes. Even degree morphology is not restricted to adjectives and languages such as Jalonke (Mande) combine verbs with degree morphemes. The prefix $m a$ - in Jalonke either functions as a distributive marker (7) expressing a multiplicity of actions or it is used as a degree expression with verbs as in (8).

Jalonke (Mande, Lüpke 2005: 309)

(7) Nxo ma-giri xure-n' i.

1PL.E DISTR-cross stream-DEF at

'We crossed the stream a lot.'

Jalonke (Mande, Lüpke 2005: 308)

(8) a. bundaa ma-bundaa

'be wet' 'be a little wet'

b. fisa ma-fisa

'be better' 'be a little better'

In the case of adjectives, gradation affects the gradable property expressed by the adjective. Gradation has the effect of further specifying the degree of the property of the referent of the adjective by comparing it to some other degree (cf.

3 Throughout this paper I use the terms 'gradation' and 'intensification' interchangeably. 


\section{Degree Expressions at the Syntax-Semantics Interface}

Bierwisch 1989, Kennedy 1999 among others). The comparandum can either be explicitly represented, as in the comparative or equative construction, or it can be a context-dependent standard value as in (5c). ${ }^{4}$ For very Kennedy \& McNally (2005) assume that it introduces a context-dependent standard value, which is conceived as 'high' in the given context. (6c) then has the reading that among those who are tall his tallness is conceived of as (contextually) high, meaning he is not only tall but tall to a high degree.

Gradation as illustrated by the examples above and in the first section can intuitively be described as the specification of the degree of a property, which allows for variable instantiation. Formally, this is captured by the notion of 'scale,' meaning that gradable properties are analyzed as scalar predications. Scales are understood as linearly ordered degrees in a certain dimension and can be formally described by three parameters: a measurement dimension $(\Delta)$ such as WIDTH or PRICE, a set of values (D), for example, size or price values, and an ordering relation $(\mathrm{R})$ that determines the linear order of the degrees (Kennedy \& McNally 2005). Different analyses of gradable adjectives are proposed in the literature (cf. Kennedy 1999 for an overview of the discussion) and the currently most popular ones assume a degree-based analysis. ${ }^{5}$ Gradable adjectives somehow encode a scale in their lexical semantics and gradation is related to a specification of a degree on that scale.

Gradation is more complex for verbs than it is for adjectives. There are at least two reasons for that higher complexity on the side of verbs. First, although all gradable adjectives are analyzed as expressing scalar predications, most verbs are not considered to express scalar predications. Rappaport Hovav (2008) and Rappaport Hovav \& Levin (2010) argue that only verbs expressing a directed change in a single dimension are scalar. This leads to the claim that only lexical change of state verbs like broaden, widen or grow and a subset of verbs of directed motion such as rise and enter are scalar. Basically, all activity predicates like bleed or hit are considered as expressing nonscalar changes, whereby 'change' is understood in the sense of Dowty (1979) and is used to capture dynamicity. ${ }^{6}$

\footnotetext{
4 Kennedy \& McNally (2005) among others also assume that the positive form of adjectives expresses a comparison with a standard value.

5 Note that there have also been nondegree based analyses of gradable adjectives - for example, Klein (1980).

${ }^{6}$ Beavers (2011) also argues for a latent scalar structure of verbs of impact like hit.
} 
The German examples in (9) indicate that gradability is not restricted to scalar verbs in the narrow sense of Rappaport Hovav \& Levin, but also activities such as bluten 'bleed' and states like lieben 'love' can be graded. ${ }^{7}$ In (a), sehr specifies the quantity of emitted blood, whereas in (b) the degree expression is used to indicate the intensity of the boy's love. (c) shows an example of a degree gradation of a scalar verb in the narrow sense of Rappaport Hovav \& Levin. In this case, sehr specifies the degree of change (see Hay et al. 1999 as well as Fleischhauer 2013, 2016 for the discussion of such cases).

(9) a. Der funge blutet sehr.

the boy bleeds very

'The boy is bleeding a lot.'

b. Der funge liebt seine Mutter sehr.

the boy loves his mother very

'The boy loves his mother very much.'

c. Der Junge ist sehr gewachsen.

the boy is very grown

'The boy has grown a lot.'

Up to now, there has been no clear notion of scalarity of verbs and Rappaport Hovav \& Levin's distinction between scalar and nonscalar changes does not coincide with gradability. This shows that scales are independent of the notion of 'change' and that it is an open question whether gradability of verbs depends on some specific property (and is therefore predictable) or not (cf. Tsujimura 2001 for a discussion of gradability of verbs in Japanese).

The second argument for the higher complexity of verb gradation compared to adjectives is that, contrary to adjectives, verbs denote eventualities. Verb gradation can either be related to specifying the degree of a gradable property lexicalized by the verb (degree gradation as in (9)) or it can be related to a gradable property of the event (extent gradation as in (10)). German uses sehr 'very' for degree gradation and viel 'much' for extent gradation. In (10a) it is the frequency of raining events that is specified by viel, whereas it is the temporal duration of the sleeping event in (b).

7 See Gamerschlag (2014) and Fleischhauer \& Gamerschlag (2014) for the argumentation that stative verbs can be distinguished into scalar and nonscalar ones similarly to Rappaport Hovav \& Levin's partitioning of dynamic verbs. 
(10) a. Letzten Sommer hat es viel geregnet.

last summer has it much rained

'Last summer, it rained a lot.'

b. Letzte Nacht hat der Junge viel geschlafen.

last night has the boy much slept

'The boy slept a lot last night.'

Extent gradation is restricted to eventive predications and hence not possible with attributively used adjectives. Predicatively used adjectives allow extent gradation as (11) indicates.

(11) Der Junge ist viel krank.

the boy is much ill

'The boy is ill a lot.'

As the data in (9) and (10) show, German uses different degree expressions for extent and degree gradation, just like Polish does. French, as shown in (12), is like English in using the same degree expression for extent and degree gradation. In (12a) beaucoup 'a lot' specifies the frequency of going to the cinema, whereas in (b) it is the degree of appreciation. The example in (c) is ambiguous in the sense that both a durative and frequentative interpretation of beaucoup are possible, which means that John either slept for a long time or that he slept often during some implicit period of time.

(12) a. Jean va beaucoupau cinéma.

Jean goes a lot to.the cinema

'Jean goes to the movies a lot.' (Doetjes 2007: 685)

b. Jean a beaucoup apprécié ses conseils.

Jean has a lot appreciated his advice

'Jean appreciated his advice a lot.' (Abeille et al. 2004: 186)

c. Jean a beaucoup dormi.

Jean has a lot slept

'John slept a lot.'

The frequency reading of extent gradation is nearly synonymous to corresponding sentences that contain frequency adverbs such as French souvent 'often' (13). Different authors, such as de Swart (1993) and Abeille et al. (2004), analyze fre- 
quency adverbs as quantifiers. Beaucoup, on the other hand, is not treated as a quantifier due to its use in degree contexts like (12b). Bosque \& Masullo (1998) go even further and subsume Spanish examples like those in (14) under the label 'verbal quantification.'

(13) Jean va souvent au cinéma. Jean goes often to.the cinema 'Jean goes to the movies a lot.'

(14) a. Llovió muy poco. rained very little 'It rained very little.' (Bosque \& Masullo 1998: 19)

b. Dormir un poco.

sleep a bit 'Sleep a little bit.' (Bosque \& Masullo 1998: 26)

c. Ir poco en tren.

go little by train

'Go rarely by train.' (Bosque \& Masullo 1998: 25)

Example (14a) corresponds to Bolinger's degree gradation, whereas those in (b) and (c) are instances of extent gradation. Bosque \& Masullo assume that (un) poco 'a bit/little' functions as a quantifier in all cases in (14), but do not provide arguments for this view. This is probably an overgeneralization from the more well-studied case of adnominal quantification to less studied cases such as those in (14). In the next section, I discuss the cross-categorical distribution of degree expressions in more detail and turn to the question whether expressions such as mucho, beaucoup or viel are really quantifiers or not in section 8 .

\section{Cross-categorical distribution of degree expressions}

In the last section, Bosque \& Masullo's claim that gradation is a subtype of quantification was mentioned. A possible reason for this assumption, which I rejected, could be the cross-categorical distribution of degree/quantity expressions. The Spanish degree expressions mucho 'a lot' and (un) poco 'a bit/little' are used ad- 
verbially as well as adnominally. ${ }^{8}$ As already pointed out in the previous sections, French, but also Spanish and English, show a different cross-categorical distribution of degree expressions from the distribution found in German and Polish. I will distinguish three contexts in which degree expressions are used: they can be used as adverbial, adnominal or adadjectival degree expressions. Starting with the adnominal use, the examples in (15) and (16) show that French and German use beaucoup and viel respectively for specifying a quantity of mass as well as count nouns. German indirectly displays the mass/count distinction by the inflection of viel. In the case of plural count nouns, viel is also inflected for plurality (16b), whereas the plurality marking is absent if it modifies a mass noun (a). In French, beaucoup is neutral with regard to the mass/count distinction and does not show an overt reflex of it. English a lot is like French beaucoup and only much and many are sensitive to the mass/count dichotomy.

(15) a. beaucoup de soup

a lot of soup

'much soup'

b. beaucoup de livres

a lot of books

'many books'

(16) a. viel Suppe

much soup

'much soup'

b. viele Bücher

much.PL books

'many books'

The examples in (17) and (18) show the combination of degree expressions with the positive form of adjectives as well as comparatives in French and German. French uses très 'very' for the positive form but beaucoup for the comparative. In addition to this, in German different degree expressions are used for intensifying the positive and comparative form of adjectives. For the positive, German uses sehr, whereas it makes use of viel for the comparative. In both languages the

8 While Bosque \& Masullo argue that degree is a subtype of quantity, Sapir (1944: 93) argues that "grading [...] precedes measurement and counting" and Gary (1979) takes degree and quantity as manifestations of the same category. 
expression used for grading comparatives is the same one that is also used in adnominal contexts, whereas the positive requires a different intensifier.

(17) a. Paul est très $/{ }^{*}$ beaucoup grand.

Paul is very/much tall

'Paul is very tall.'

b. Paul est beaucoup/ ${ }^{*}$ très plus grand que Daniel.

Paul is a lot/very more tall than Daniel

'Paul is much taller than Daniel.'

(18) a. Paul ist sehr ${ }^{*}$ viel groß.

Paul is very/*much tall

'Paul is very tall.'

b. Paul ist viel/*sehr größer als Daniel.

Paul is much/*very taller than Daniel

'Paul is much taller than Daniel.'

The adverbial context has already been discussed in the last section. The examples in (9) and (10) for German and in (12) for French revealed that German uses sehr for degree gradation and viel for extent gradation, whereas French uses beaucoup for both. French and German show a slightly different cross-categorical distribution of the degree expressions discussed in this section. In French, it is only the positive form of adjectives that requires a different intensifier. German marks both gradation of adjectives in the positive form as well as degree gradation of verbs similarly. Table 1 summarizes the distribution of degree expressions for French, English, Spanish, German, Bulgarian and Polish. In addition, data from two non-Indo-European languages are included in the table. Finnish (FinnoUgric) has the same pattern that also shows up in French and Spanish, whereas Tatar (Turkic) is like German and Polish. ${ }^{9}$ It is not always the case that languages use a different intensifier for adjectives in the positive than they use for the other degree contexts. Bulgarian, for example, makes use of mnogo 'very, a lot' in all the contexts distinguished in table $1 .^{10}$

9 The data from Tatar and Bulgarian are shown in the appendix. The data of the other languages have already been discussed throughout the paper, except Finnish. The Finnish data are taken from Karttunen (1975). For a broader cross-linguistic investigation of the distribution of degree expressions see Fleischhauer (2016).

${ }^{10}$ An anonymous reviewer mentioned that colloquial Serbian also uses mnogo in all the contexts mentioned above. 
Degree Expressions at the Syntax-Semantics Interface

\begin{tabular}{|l|l|l|l|l|l|l|}
\hline \multirow{2}{*}{ Language } & \multicolumn{2}{|c|}{ adjectival domain } & \multicolumn{2}{c|}{ nominal domain } & \multicolumn{2}{c|}{ verbal domain } \\
\cline { 2 - 7 } & Positive & Comparative & Mass & \multicolumn{1}{c|}{ Count } & \multicolumn{1}{c|}{ Extent } & \multicolumn{1}{c|}{ Degree } \\
\hline French & très & beaucoup & beaucoup & beaucoup & beaucoup & beaucoup \\
\hline English & very & a lot & a lot & a lot & a lot & a lot \\
\hline Spanish & muy & mucho & mucho & mucho & mucho & mucho \\
\hline Finnish & hyvin & paljon & paljon & paljon & paljon & paljon \\
\hline Bulgarian & mnogo & mnogo & mnogo & mnogo & mnogo & mnogo \\
\hline German & sehr & viel & viel & viel & viel & sehr \\
\hline Polish & bardzo & dużo & dużo & dużo & dużo & bardzo \\
\hline Tatar & bik & küp & küp & küp & küp & bik \\
\hline
\end{tabular}

Table 1: Cross-categorical distribution of degree expressions.

Table 1 merely lists eight languages, which does not allow for any conclusive typological generalizations. Nevertheless, it shows that in these languages the expression used for verbal extent gradation is also always used as an adnominal quantity expression. And if a language has different expressions for extent and degree gradation, the expression used for degree gradation also applies to the positive form of adjectives. It has to be mentioned that languages usually have several synonymous degree expressions which can differ in their distribution, as is the case for English (very) much and a lot. Only the latter is used for extent gradation and used as an adnominal quantity expression. Hence the claims made in this section have to be substantiated by looking at a larger range of data and also by looking into more languages. But at the present stage, I have decided to concentrate on the most neutral degree expressions, meaning such expressions that do not convey emphatic content and have the broadest distribution. For German, these are sehr and viel, even if several hundred intensifiers can be listed for German (see Van Os 1989).

In section 8, I will argue that it is no accident that German, for example, uses viel rather than sehr for extent gradation. But first, I focus on the difference between verbal extent and degree gradation and thereby follow Doetjes (1997) in assuming that expressions like French beaucoup are not semantically ambiguous in terms of expressing a high degree and a high frequency. Assuming a uniform semantics for these expressions, I will rather show in the next section that beaucoup is syntactically ambiguous. 


\section{Syntactic ambiguity of beaucoup}

The aim of this section is to show that the adverbially used French degree expression beaucoup is syntactically ambiguous. With 'syntactically ambiguous' I mean that an expression can be used in two clearly distinct syntactic configurations which are associated with two different semantic interpretations. Two arguments will be presented in support of this claim. First, it will be shown that adverbial beaucoup allows for multiple realizations in a single sentence. It can simultaneously be realized as a degree as well as an extent intensifier. Second, it will be shown that the syntactic position of beaucoup constrains its interpretation. Similar claims are made by Vecchiato (1999), who argues that differences in the syntactic distribution of degree and extent beaucoup as well as the multiple realization of beaucoup indicate an apparent syntactic ambiguity of the degree expression. Working in the cartographic enterprise of Cinque (1999), she claims that the data indicate that extent and degree beaucoup are related to two different functional projections in the clause. But in the end, she assumes the same functional projection for both uses without an indication of how the different readings of beaucoup arise. My analysis differs from hers in assuming that beaucoup is really and not only apparently syntactically ambiguous and that the difference between extent and degree gradation arises through two different syntactic configurations in which beaucoup can be used.

In (19) the multiple realization of beaucoup is shown. The degree adverb is realized twice in the sentence and this leads to a specification of the frequency of bleeding events as well as to the degree of bleeding. It is the quantity of blood emitted in the event that is specified in the degree interpretation of beaucoup. If each linguistic category can only be specified once, the example in (19) shows that extent and degree beaucoup are related to the expression of different linguistic categories. Taken alone this does not show that there is also a syntactic difference between both uses of beaucoup, but it suggests that degree and extent intensifiers belong to two different semantic classes of adverbs.

(19) Il a beaucoup saigné beaucoup de nez.

he has a lot bled a lot from nose 'He often bled out of his nose a lot.' 
It can be more clearly shown which use of beaucoup in (19) contributes the frequency and which one contributes the degree interpretation. The examples in (20) help to identify the syntactic positions and how they are related to the interpretation of beaucoup. If beaucoup is placed between the auxiliary and the main verb (20a), it is ambiguous as to whether a degree or an extent interpretation is possible. But as the examples in (b) and (c) show there are two unambiguous positions for beaucoup. If beaucoup directly follows the main verb, it can only be interpreted as a degree intensifier. Following the undergoer argument beaucoup only allows for an extent interpretation. For (19) this means that the first occurrence of beaucoup has to specify the event's frequency, since the syntactic position of the second one only allows for the degree reading.

(20) a. Il a beaucoup admiré cette chanteuse à l'opera.

he has a lot admired this chanteuse at the opera

'He has (often) admired this chanteuse (very much) at the opera.'

b. Il a admiré beaucoup cette chanteuse à l'opera

'He has admired this chanteuse very much at the opera.'

c. Il a admiré cette chanteuse beaucoup à l'opera.

'He has often admired this chanteuse at the opera.'

The sentences in (21) indicate that the syntactic position of beaucoup really puts constraints on its interpretation. The main clause in the examples contains beaucoup in a position between the auxiliary and the main verb (a) and following the main verb in (b). In the subordinate sentence a degree specification is added, which introduces an inconsistent degree specification with that of beaucoup. Un peu 'a little bit' indicates a low degree, whereas beaucoup specifies a high degree. Example (b) is contradictory since it would simultaneously express that he emitted a large quantity of blood (main clause) but that the quantity of blood he emitted was small (subordinated clause). The sentence is contradictory since beaucoup allows only for a degree reading in the position after the participle. If beaucoup is placed between the auxiliary and the participle, no contradiction arises since it allows for a frequency reading. Sentence (21a) has the interpretation that he often bled, but only emitted a small quantity of blood.

(21) a. Il a beaucoup saigné du nez, mais seulement un peu. he has a lot bled of.the nose but only a little bit 'He often bled out of his nose, but only a little bit.' 
b. \#Il a saigné beaucoup du nez, mais seulement un peu. he has bled a lot of.the nose but only a little bit 'He bled a lot out of his nose, but only a little bit.'

The data in this section have shown that the interpretation of beaucoup is constrained by the syntax. This leads to the claim that extent and degree gradation are related to two different syntactic configurations. ${ }^{11}$ In the next section, I will present RRG's view on adverbs, before I come to my analysis of the syntax of adverbially used degree expressions in section 6.

\section{Adverbs in RRG}

Role and Reference Grammar assumes different structured representations for predicates, their arguments and adjuncts on the one hand and grammatical operators on the other. These representations are called 'constituent' and 'operator projection' respectively (Van Valin \& LaPolla 1997, Van Valin 2005). Operators are expressions for grammatical categories such as tense and aspect. Both, the constituent and the operator structure, are built on the same semantically motivated layered structure of the clause. RRG distinguishes between nucleus, core and clause layers (leaving the sentence level aside). The nucleus contains only the predicate, irrespective of whether it is a verb or some other predicating element such as a predicatively used adjective. The core consists of the nucleus and the arguments of the predicate. The highest layer - clause - contains the core and some optional elements (cf. Van Valin 2005). Each layer has an optional periphery that contains adjuncts and adverbials. Figure 1 gives a schematic representation of the layered structure of the clause and the connection of the constituent and the operator projection. Both structures are a mirror image of each other and are connected through the predicate.

Adverbs are realized in the periphery of the constituent projection and can attach to each of the three layers of the clause. Unlike in other approaches, such as Cinque (1999), it is not assumed that adverbs have a fixed base position. Nevertheless, the positioning of adverbs is not totally unconstrained. If multiple adverbs are realized in a sentence, the layered structure of the clause constrains their

${ }^{11}$ The analysis presented in this paper differs from the one by Doetjes (1997) who assumes there is no syntactic difference between the extent and degree interpretation of beaucoup. 


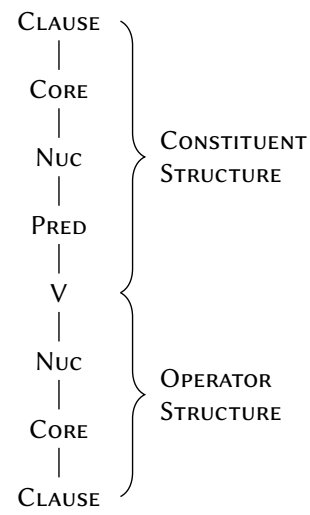

Figure 1: Schematic representation of constituent and operator projections in RRG (following Van Valin 2005: 12)

positioning. This means that the layered structure of the clause constraints the linear order of multiple adverbs. Nucleus adverbs are realized closer to the predicate than core adverbs, whereas core adverbs are again closer to the predicate than clausal ones (Van Valin 2005: 21). Also, a relationship between adverbs and operators is proposed. Adverbs are not operators, but "adverbs related to more outer operators occur outside of adverbs related to more inner operators" (Van Valin 2005: 20). Hence, the order of adverbs matches the order of operators to the extent that they semantically correspond to each other. Innermost operators are those specifying the nucleus, whereas the outermost ones are clausal operators. A list of operator types is shown in (22). Nuclear operators modify the action or event, whereas core operators are concerned with the relation between the nucleus and its arguments. Finally, clausal operators modify the whole clause.

(22) a. Nucleus operators: aspect, negation, directional

b. Core operators: directionals, event quantification, modality, negation

c. Clause operators: status, tense, evidentials, illocutionary force (Van Valin 2005: 12)

As mentioned above, adverbs and operators can semantically correspond to each other in expressing the same semantic category, such as aspect. Grammatical aspect can either be expressed by grammatical operators, like -ing in English, or such adverbs as continuously. As a first indication, one can assume that adverbs are realized at the same syntactic layer as their corresponding operators. The 
order of operators can therefore be roughly used as an indication of the syntax of corresponding adverbs. But this is not a perfect correspondence since tense is considered to be a sentence operator, whereas temporal adverbials are treated as core adverbs (Van Valin \& LaPolla 1997: 162).

There is no discussion of degree operators in RRG (as example (8) from Jalonke showed, some languages have such operators in the verbal domain), but event quantification, which I consider similar to extent gradation, is discussed. Amele (Papua-New Guinea) has a distributive morpheme - $a d$ - which indicates a multiplicity of actions. This can be seen by the example in (23a), in contrast to (b) which expresses a single action.

Amele (Papua-New Guinea; Roberts 1987, cited after Van Valin 2005: 11)

(23) a. Age bel-ad-ein.

3PL go-DISTR-3PL.REMPST

'They went in all directions.'

b. Age bel-ein.

3PL go-3PL.REMPST

'They went.'

Van Valin argues that event quantification is a core layer operator. There are two arguments in support of this view: first, the distributive morpheme is closer to the stem than the tense operator. Tense is taken to be a clause operator and clausal operators occur outside of core operators. Athapaskan languages also show that nucleus operators are closer to the stem than distributive morphemes. In Slave, the inceptivity and perfectivity markers are realized to the right of the distributive morpheme $y a ́$ - (19). Rice (2000) discusses the order of verbal affixes in Athapaskan languages and shows that the order of aspect and distributive marker shown in (24) also holds for other Athapaskan languages such as Koyukon, Athna and Deni'ina.

Slave (Athapaskan; Rice 1989: 678, Rice 2000: 52)

(24) yá-d- $i-t a$

DISTR-INCEP-PERF-kick

'It kicked many times.'

The data in (23) and (24) show that distributive morphemes have to follow nucleus operators such as aspect and that they precede clause operators as tense. 
The second argument in favor of analyzing event quantification as an operation at the core layer is that the core is the minimal expression of an event (Van Valin 2005: 11). At the core, all semantically necessary components of an event - the event predicate and the event participants (Bohnemeyer \& Van Valin 2013) - are realized. The nucleus is too small to be a syntactic expression of the event since it only contains the predicate but not the event participants. Also, operators that locate the event, either temporal or spatial ones, are core/clausal operators and therefore not present at the nucleus layer (Bohnemeyer \& Van Valin 2013: 13). Therefore, operators that specify the quantity of an event are realized at the core layer or even higher up in the layered structure of the clause.

Based on Van Valin's analysis of event quantifiers as core operators, I predict that adverbial extent intensifiers should be core adverbs. In the next section I will provide the crucial data that show that this prediction is true. A similar prediction for adverbial degree intensifiers cannot be derived from the analysis of operators in RRG. However, the next section will show that degree intensifiers are nucleus adverbs and therefore differ syntactically from extent intensifiers.

Before I turn to the discussion of the crucial data, a short note on methodology is in order. Van Valin, following Jackendoff (1972), proposes that the relative order of adverbs reflects semantic scope relationships. Hence, analyzing the relative order of adverbs allows determining the syntax of adverbs. ${ }^{12}$ A complicating factor is that information structure can affect the order of adverbs as shown by Maienborn (1996, 2001) for locative adverbials in German. The German examples in (25) show that no fixed order of the degree intensifier sehr and the directional adverbial aus der Nase 'out of the nose' can be established. ${ }^{13}$ Sehr can either follow or precede the directional and no semantic difference exists between the sentences. Nevertheless, native speakers agree that the sentence in (a) is preferred, even if (b) is fully grammatical.

(25) a. Er hat sehr aus der Nase geblutet.

he has very out the nose bled 'He bled a lot out of his nose.'

${ }^{12}$ This kind of approach to the syntax of adverbs is also used in generative frameworks such as Cinque (1999).

${ }^{13}$ Van Valin (p.c.) mentions that aus der Nase is probably an argument adjunct rather than an adverbial. I leave this question open for future work since it does not affect the principals of the current analysis. 
b. Er hat aus der Nase sehr geblutet.

he has out the nose very bled

'He bled a lot out of his nose.'

To determine the relative order of adverbs, it would be necessary to discuss information structure, which goes beyond the limits of the current paper. I will use a different strategy and base my analysis on scope relationships that exist between degree adverbs and aspectual operators.

\section{Scope relationships}

In this section, I will show that degree and extent intensifiers have different scope relationships with regard to grammatical aspect. It will be shown that extent intensifiers have scope over grammatical aspect, whereas grammatical aspect has scope over degree intensifiers. Scope can informally be defined as "a relational notion, where the interpretation of one expression depends on another one in a certain way" (de Swart 1998: 29). If extent intensifiers have scope over grammatical aspect, then the interpretation of aspect should be constrained or influenced by the intensifier. On the other hand, if aspect operators have scope over degree intensifiers, the interpretation of degree gradation should be affected by grammatical aspect.

Generally speaking, grammatical aspect is a distinction between a perfective and an imperfective description of a situation (cf. Comrie 1976). Under a perfective description, a situation is conceived as complete and without reference to its internal structure. Imperfective aspect, on the other hand, is more diverse and subsumes the progressive, continuous, and habitual subtypes. In all these cases, a situation is not (necessarily) described as complete but rather with reference to its internal structure. The continuous and progressive aspect describes a situation as ongoing, whereas habitual aspect indicates that a certain type of situation is characteristic for an extended interval.

French has a grammaticalized aspect distinction in the past tense between a perfective past (passé compose) and an imperfective past (imparfait). German does not have one, but provides different strategies for the expression of aspect. The German Perfekt, for example, substitutes for the perfective aspect in some contexts. But the Perfekt is also compatible with an imperfective state of affairs (cf. 
Löbner 2002). Both French and German, also make use of a periphrastic progressive construction which can be combined with all tenses. In the French construction, the inflected auxiliary être 'to be' is combined with en train de 'in the process of' and the main verb is realized as an infinitive (26a). German uses a construction consisting of the inflected auxiliary sein (to be), a contracted form of the preposition $a n(a t)$ and the definite article in dative case which is realized as am 'at.the' and the main verb as a nominalized infinitive (26b). This construction is called the 'rheinische Verlaufsform' and is often mentioned as being restricted to northern dialects. Ebert (2000), for example, shows that this construction is developing towards a grammaticalized progressive construction in colloquial German.

(26) a. Nous sommes en train de rénover notre maison.

we are PROG renovate our house

'We are renovating our house.'

b. Wir sind unser Haus am Renovieren.

we are our house at.the renovating

'We are renovating our house.'

Starting with German, the examples in (27) show the combination of the degree intensifier sehr with a verb in the perfective (a) and progressive aspect (b). The perfective sentence in (a) has the interpretation that the total amount of blood emitted in the course of the event is large. A paraphrasing of the sentence is 'the boy emitted a lot of blood.' For the progressive sentence in (b) the interpretation is different. Sehr does not specify the total amount of emitted blood, but the amount of blood emitted at a certain stage of the event. Since the progressive describes an ongoing event, no reference to the total amount of blood is possible. Also, both interpretations do not entail each other. If someone emitted a lot of blood during an event, he does not necessarily emit a lot of blood at each stage of the event. Rather he could only emit a bit of blood at each stage of the event which adds up to a large amount over the course of the whole event. Also, if one emits a lot of blood at a single stage of an event, it does not mean that the total quantity of blood has to be large as well. These are two related, but distinct interpretations of degree gradation that depend on the choice of grammatical aspect.

(27) a. Der Junge hat sehr geblutet.

the boy has very bled

'The boy bled a lot.' 
b. Der funge war sehr am Bluten.

the boy was very at.the bleeding

'The boy was bleeding a lot.'

The same effect of aspect on the interpretation of the degree use of beaucoup can be found in French (28). In (28a) we get the total quantity interpretation for the perfective verb and for the verb used in the progressive construction we get a specification of the quantity of blood emitted at a certain stage of the event. In contrast to the German example in (27a), the perfective sentence in (28a) also licenses an extent reading of the intensifier. Beaucoup does not give rise to an extent reading in the progressive sentence in (b).

(28) a. Il a beaucoup saigné.

he has a lot bled 'He bled a lot.'

b. Il est en train de saigner beaucoup.

he is PROG to bleed a lot

'He is bleeding a lot.'

German allows the combination of the adverbially used extent intensifier viel with verbs in the perfective (29a) as well as progressive aspect (b). In the case of the perfective verb bluten 'bleed' in (a) viel specifies the frequency of bleeding events. The sentence can be paraphrased as 'last week, the wound bled often.' Also, in combination with the progressive in (b) viel specifies the frequency of the event and the sentence can be paraphrased as 'the wound was bleeding often.' This frequency interpretation is incompatible with the meaning of the progressive, as describing a single, ongoing event. In the context of extent gradation, the progressive is shifted towards a habitual interpretation of the imperfective aspect. Comrie observes the same effect for English examples as in (30). A lot specifies the frequency of events denoted by the perfective verb in (a), but it has the same effect with the progressive verb in (b). Comrie (1976: 37) mentions that (30b) is an example of a habitual interpretation of the English progressive aspect. Even without these days, a lot would force a habitual interpretation of the progressive verb, which shows that it really is the extent intensifier that constrains the interpretation of grammatical aspect. 
(29) a. Letzte Woche hat die Wunde viel geblutet.

last week has the wound much bled

'Last week, the wound bled a lot.'

b. Die Wunde war viel am Bluten.

the wound was much at.the bleeding

'The wound was bleeding a lot.'

(30) a. We have gone to the opera a lot (these days).

b. We're going to the opera a lot these days.

(Comrie 1976: 37)

The German and English examples have shown that the interpretation of extent gradation does not change depending on the choice of grammatical aspect. Rather it is the other way round and progressive aspect is shifted towards a habitual reading by the extent intensifier. This is expected given the incompatible requirements of the frequency reading of extent gradation, which requires a multiplicity of events, and the progressive aspect, which describes a single and ongoing event. As aspect shifts in its interpretation, it is reasonable to conclude that extent intensifiers have scope over aspect. One open question is why French does not allow for an extent reading of beaucoup with verbs used in the periphrastic progressive constructions. Answering this question would go beyond the limits of this paper.

This section has shown that extent and degree intensifiers have different scope relationships with regard to grammatical aspect. Extent intensifiers have scope over grammatical aspect, whereas grammatical aspect has scope over degree intensifiers. In the next section, I will show what this reveals for a RRG analysis of the syntax of degree and extent intensifiers.

\section{Syntax of verb gradation}

The last section has shown that extent and degree intensifiers differ in scope relationships with regard to grammatical aspect. I assume that semantic scope relationships are also syntactically reflected. Since grammatical aspect is expressed by nucleus operators, degree gradation has to be located at the nucleus layer too. Degree intensifiers therefore have to be nucleus adverbs; otherwise aspect could not have scope over degree gradation. Extent intensifiers do not fall under the scope of aspect, which perfectly fits the assumption formulated in section 5 that 
extent gradation is expressed at the core layer. Based on this prediction, I assume that adverbially used extent intensifiers are core adverbs. It follows that degree and extent gradation are realized at two different syntactic layers. The difference between German viel and sehr is basically a syntactic one. Since adverbial viel is an extent intensifier, it is a core adverb, whereas the degree intensifier sehr is a nucleus adverb. Figure 2 shows the syntactic structure of the sentence $\mathrm{Er}$ hat sehr geblutet 'He bled a lot' on the left and Er hat viel geblutet 'He bled a lot' on the right. A note on the representation of the aspectual operator is required. As discussed above, the German Perfekt cannot be conceived as expressing perfective aspect. But since each sentence has an aspectual interpretation, I assume an aspectual operator, but it is not the Perfekt construction in German does functions as an expression of perfective aspect. Therefore aspect is not linked to a certain constituent in the constituent structure.

French adverbially used beaucoup is ambiguous between a degree and extent reading. Both readings are related to different syntactic configurations, as has been shown in section 4 . Given the data discussed in the last section, it is reasonable to conclude that beaucoup in its extent use is realized at the core layer, whereas the degree interpretation of beaucoup arises if it is used as a nucleus adverb. Figure 3 shows the syntactic trees for verbal degree gradation (left) and extent gradation (right) in French. Syntactically, extent and degree gradation are realized in the same way in German and French, the only difference is that beaucoup is syntactically ambiguous between being a nucleus as well as core adverb, whereas the corresponding German degree expressions are not.

The syntactic difference between extent and degree gradation is semantically motivated. Degree gradation affects a gradable property lexicalized by the verb; therefore the intensifier directly applies to the verb. In case of bluten 'bleed', the gradable property is a volume scale, measuring the volume of the emitted substance. Extent gradation does not affect a gradable property of the verb but is an attribute of the event. Temporal duration and frequency are gradable properties of the event itself and not of the verb. Hence two different sources contribute the scales for verb gradation and the syntactic distinction discussed above is merely a reflection of this fact.

The distinction between extent and degree gradation can be reduced to a syntactic one and a uniform semantic analysis of adverbial degree expressions is possible. Adverbial intensifiers always specify a degree on a scale and only the 

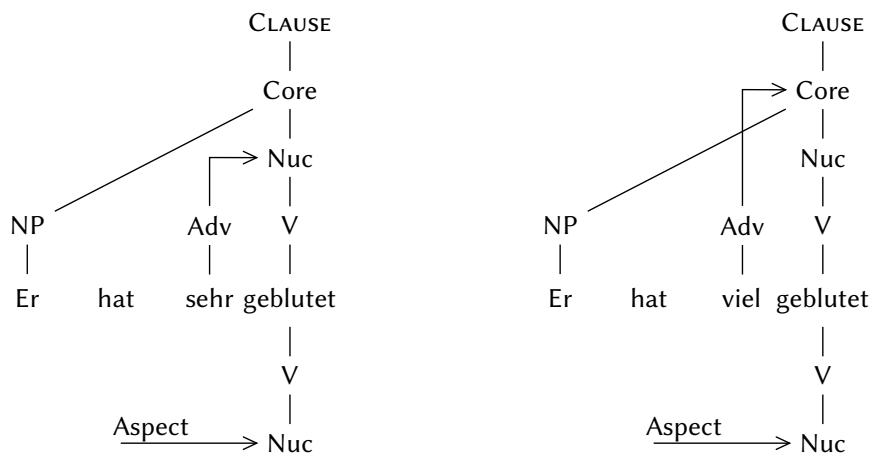

Figure 2: Syntactic structure of verbal degree gradation (left) and extent gradation (right) in German. ${ }^{14}$
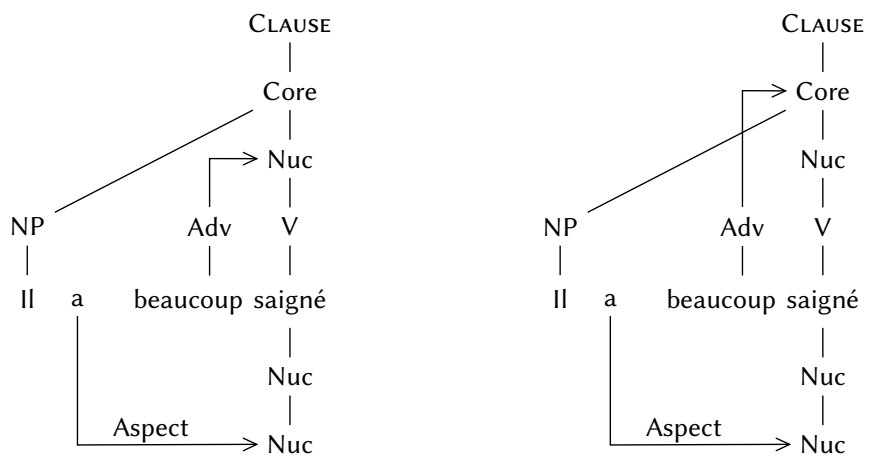

Figure 3: Syntactic structure of verbal degree gradation (left) and extent gradation (right) in French.

source of the scale determines whether it results in degree or extent gradation. Languages such as German, Polish or Tatar, which use different adverbs for extent and degree gradation, use different adverbs depending on the source of the scale. If the scale is contributed by the verb, a degree intensifier is used. But if the event contributes the scale, an extent intensifier is used for gradation. French, Spanish and also English do not overtly distinguish between adverbial degree and extent intensifiers, but rather have a syntactically ambiguous general degree expression. It is the syntactic configuration in which the degree expression is used that determines whether it results in degree or extent gradation.

\footnotetext{
${ }^{14}$ Van Valin (2008) argues that the nominal of 'NP' has to be replaced by the notion of a 'referential phrase' (RP). Since this does not affect my analysis, I stay with the more traditional term NP.
} 
For indicating scope relationships, which are only implicit in the syntactic trees above, RRG makes use of lexical decomposition. The original intention of lexical decomposition in RRG is not to represent scope relationships but to determine the linking of the verb's arguments. Therefore the decompositional system, which is based on Dowty (1979), is used to capture the grammatically relevant components of verb meaning. RRG builds its lexical decomposition on Vendler's (1957) system of aktionsart classes, which I will not discuss in detail (for a full overview of the lexical decompositions assumed in RRG cf. Van Valin 2005). Van Valin assumes two basic types of predicates: states and activities. Activities are either oneor two-place predicates that are always marked by the operator do'. This is a two-place operator which takes the actor as its first argument and the predicate denoting the activity as its second one. The predicate decomposition for the verb bluten is shown in (31).

\section{(31) bluten do' $(\mathrm{x}$, bleed'(x))}

Adverbs are represented in the predicate decompositional system as one-place predicates that modify logical structures or parts of logical structures. Operators, on the other hand, which do not receive a semantic interpretation in RRG, are merely indicated by angled brackets in the logical structures. In (32a) the (partial) logical structure for German extent gradation - hat viel geblutet 'has bled a lot' - is shown. viel' takes the activity predicate as well as the aspectual operator in its scope. In (b) the logical representation for degree gradation is indicated. sehr' only has the logical structure representing the activity predicate in its scope, whereas the aspectual operator precedes the adverb. The representations in (32) clearly allow the indication of the scope relationships, even if operators and adverbs are realized in two different projections.

(32) a. hat viel geblutet viel' $(\langle$ ASP PERF ( do'(x, bleed'(x)) $\rangle)$

b. hat sehr geblutet $(\langle$ ASP PERF (sehr'( do'(x, bleed'(x))) $\rangle)$

Although the representations in (32) can be used to indicate scope relationships, they are not sufficient to explain differences with respect to verb gradation which show up between verbs belonging to the same semantic class (in the sense of Levin 1993). First, verbs differ with regard to the scale they lexicalize. Compare bluten, which was discussed above, with another verb of emission like dröhnen 
'drone'. Dröhnen is a verb of sound emission and example (33) has the interpretation that the intensity of the sound (meaning the loudness) is high. Both dröhnen and bluten are activity predicates and belong to the same semantic class; hence they do not differ with respect to lexical decomposition (34). Nevertheless, with respect to degree gradation both verbs differ in lexicalizing different types of scales. This difference between the verbs can only be captured by a deeper lexical decomposition, which further decomposes the constant elements (cf. Löbner 2012 for a similar claim).

(33) Der Motor hat sehr gedröhnt.

the engine has very droned

'The engine drones a lot.'

(34) a. bluten do'(x, bleed'(x))

b. dröhnen do' $\left(\mathrm{x}\right.$, drone' $\left.^{\prime}(\mathrm{x})\right)$

A second reason for a deeper lexical decomposition is that otherwise the interaction of grammatical aspect and degree gradation cannot be explained. Not all gradable verbs show an effect of grammatical aspect on degree gradation, only change of state verbs like widen, grow and stabilize and verbs of substance emission do (cf. Fleischhauer 2013, 2016). By considering the examples in (33) and (35) it can be shown that grammatical aspect does not affect degree gradation of verbs of sound emission. In the perfective example in (33) sehr specifies the sound intensity, the emitted sound is described as 'very loud.' The same interpretation obtains for the progressive sentence in (35). To explain why degree gradation interacts for some verbs with grammatical aspect and for others not requires a closer look at the semantics of the respective verbs.

(35) Der Motor ist sehr am Dröhnen.

the engine is very at.the droning

'The engine is droning a lot.'

Since the aim of this paper is to provide an explanation for the difference between extent and degree gradation, I will not go further into a discussion of an appropriate deeper lexical decomposition. The central outcome of this section is that degree and extent gradation are realized at two different syntactic layers and that this syntactic distinction is semantically motivated. In the next section, I will 
come back to the question why expressions used for extent gradation can also be used as adnominal quantity expressions but expressions restricted to degree gradation like German sehr cannot.

\section{Syntax of adnominal quantity expressions}

In the last section, I presented the claim that adverbially used viel is a core adverb, whereas sehr is a nucleus adverb. In this section, I will argue that the specification of a nominal quantity is also an operation at the core layer. The expression of an adnominal quantity is the nominal equivalent of extent gradation in the verbal domain; therefore it is not unexpected that degree expressions used for extent gradation also show up in the nominal domain.

Role and Reference Grammar proposes a layered structure of the NP analogous to the layered structure of the clause. The three layers in the case of NPs are: nominal nucleus, nominal core, which is the nucleus and the arguments of a complex derived nominal, and NP layer, which corresponds to the clause layer (Van Valin 2005: 24). As in clauses, there is also a periphery for each layer of the $\mathrm{NP}$ as well as a nominal operator projection. Van Valin (2005: 24) mentions the following nominal operators: nominal aspect (mass/count distinction, classifiers) at the nucleus layer, negation, number and quantification at the core layer and definiteness and deixis at the NP layer. With regard to core operators Van Valin (2005: 24) states that they are about quantity and NP-level operators are used to integrate the NP in discourse. Crucially, operators at the nucleus layer are taken to be restrictive modifiers, whereas those at higher layers are not (Van Valin 2005: 24).

It matters for the analysis whether we take viel to be a quantifier or an adjective. If we analyze it as a quantifier, viel would be a core $\mathrm{N}_{\mathrm{N}}$-level operator. But if we take it to be an adjective, it would not be located in the operator structure but rather be considered part of the constituent structure. With regard to their place in the constituent structure Van Valin (2005: 26) writes: “[...] adjectives are best treated on the analogy of adverbs in the clause: they are constituents of the (nuclear ${ }_{N}$ ) periphery whose position is constrained by the iconicity principle - they must occur closer to the nominal nucleus than core $\mathrm{N}^{-}$and NP-level operators and modifiers." This only holds for restrictive adjectives, since in analogy to nucleus operators all restrictive adjunct modifiers are located in the nuclear ${ }_{N}$ periphery (Van Valin 
2005: 24). Nonrestrictive modifiers are considered to be located at the NP-level periphery, whereas the core $_{\mathrm{N}}$-level periphery contains "adjunct setting NPs and adverbials of complex event expressions" (Van Valin 2005: 26). Viel is a nonrestrictive modifier and I will claim that it is located in the core $_{\mathrm{N}}$-level periphery, which is - as stated above - concerned with quantity. Starting with an argumentation in favor of viel's status as an adjective, two morphosyntactic arguments supporting this view can be put forward. First, quantity expressions like viel can be realized in a different position in the NP than quantifiers such as einige 'some'. In (36a) the order of elements in the NP is shown. The quantifier has to precede the definite article, whereas the quantity expressions viel can follow the article. Other adjectives like klein 'small' follow the quantity expression. Quantifiers are always the first element in the NP (cf., (37)), if the NP does not contain a quantifier, then the definite article is in first position (b). Viel can be in the first position of the NP only if the NP does not contain a quantifier (c) or is used in a partitive construction with a definite article in genitive case. Comparing the form of viel in (36a, b) with the one in (c, d) shows that the quantity expression has a different form if it is the first element in the NP. This leads to the second morphosyntactic argument for taking viel as an adjective.

(36) a. einige der vielen kleinen Äpfel some the many small apples 'some of the many small apples'

b. die vielen kleinen Äpfel the many small apples 'the many small apples'

c. viele kleine Äpfel many small apples 'many small apples'

d. viele der kleinen Äpfel many the.GEN small apples 'many of the small apples'

(37) * die einige kleine Äpfel the some small apples 
Quantity expressions in German decline like adjectives. German distinguishes between a weak and a strong adjectival declension (there is also a mixed type which is left aside in the following discussion). Table 2 is the paradigm for all four cases in the plural. Each cell shows the inflection of the adjective alt 'old' and the quantity expression viel. As can be seen, the quantity expression and the adjective inflect the same way. Adjectives exhibit the weak declension if, for example, they are preceded by the definite article. The strong declension is used if the adjective is the first element in the NP or if it is preceded by the indefinite article (cf. Esau 1973 for a discussion of the function of the different adjective endings in German). Quantifiers only show the strong declension, since they are never preceded by the definite article, as shown by the ordering in (36) and (37).

\begin{tabular}{|l|l|l|}
\hline \multicolumn{1}{|c|}{ Case } & \multicolumn{1}{|c|}{ Strong declension } & \multicolumn{1}{|c|}{ Weak declension } \\
\hline Nominative & $\begin{array}{l}\text { alt-e Männer } \\
\text { viel-e Männer }\end{array}$ & $\begin{array}{l}\text { die alt-en Männer } \\
\text { die viel-en Männer }\end{array}$ \\
\hline Accusative & $\begin{array}{l}\text { alt-e Männer } \\
\text { viel-e Männer }\end{array}$ & $\begin{array}{l}\text { die alt-en Männer } \\
\text { die viel-en Männer }\end{array}$ \\
\hline Dative & $\begin{array}{l}\text { alt-en Männern } \\
\text { viel-en Männern }\end{array}$ & $\begin{array}{l}\text { den alt-en Männern } \\
\text { den viel-en Männern }\end{array}$ \\
\hline Genitive & $\begin{array}{l}\text { alt-er Männer } \\
\text { viel-er Männer }\end{array}$ & $\begin{array}{l}\text { der alt-en Männer } \\
\text { der viel-en Männer }\end{array}$ \\
\hline
\end{tabular}

Table 2: Adjective declension in German, plural forms for the weak and strong declension type.

The morphosyntactic and language specific arguments presented above can be supplemented by a semantic argumentation. There is some debate on the semantic status of adnominal quantity expressions, i. e., whether they are quantifiers or rather as adjectives. Usually, quantifiers are taken in the sense of Generalized Quantifier Theory (GQT, Barwise \& Cooper 1981). In such a view, they take two set-denoting expressions (type $\langle\mathrm{e}, \mathrm{t}\rangle$ ) as arguments and make a predication about the intersection of both sets. They take two arguments and return a truth value, therefore they are of type $\langle\langle e, t\rangle\langle\langle e, t\rangle t\rangle\rangle$. Adjectives, in the semantic sense, are taken as modifiers and modifiers take an unsaturated expression as their argument and return an expression of the same type (type $\langle\langle x, t\rangle\langle x, t\rangle\rangle)$.

Adnominal quantity expressions have two different readings, which are called 'proportional' and 'cardinal' readings. The proportional reading of (38) is that a large proportion of the linguistics students signed up for the class or that the number of linguistics students that has signed up for class is large. Partee (1988) 
argues that only the proportional reading requires a quantificational analysis of many, whereas in its cardinal reading many is used as an adjective, i. e., modifier.

(38) Many linguistics students signed up for the class.

Following Partee's argumentation for adnominal quantity expressions, there is no need to postulate a quantificational analysis of beaucoup. Authors such as Hoeksema (1983), Löbner (1987a, 1987b, 1990) and Solt (2009) argue against Partee's ambiguity analysis of adnominal quantity expressions. Löbner, for example, assumes that the cardinal reading of expressions like English much/many and German viel is basic and that the distinction between cardinal and proportional readings is merely a pragmatic rather than a semantic one. He argues that information structure affects the interpretation of the adnominal quantity expression and hence there is no need to analyze them as quantifiers. I will not go into the details of the argumentation against a quantificational analysis of adnominal quantity expressions but refer the reader to the literature mentioned above and the references cited within. ${ }^{15}$ I follow Löbner's argumentation and assume that adnominal quantity expressions are adjectives rather than quantifiers. ${ }^{16}$

Taken together, there are semantic as well as morphosyntactic arguments in favor of treating quantity expressions as adjectives/modifiers rather than operators/quantifiers. But if they are adjectives, they have to be located at the nominal core layer. The reason is that viel is not only sensitive to the mass/count distinction but also to number. As (39a) shows, viel cannot combine with a singular count noun but requires a plural noun (b). Mass nouns are transnumeral and license quantity expressions (c). Morphologically Wasser 'water' is singular and also viel shows singular agreement.

$$
\begin{aligned}
& \text { a. *viel Buch } \\
& \text { much.sG book.sG }
\end{aligned}
$$

15 The same argumentation as applied to adnominal quantity expressions can be used to show that extent intensifiers function as modifiers rather than quantifiers (cf. de Swart 1993 and Abeille et al. 2004).

16 The rejection of a quantificational analysis for degree/quantity expressions does not mean that they are modifiers, rather a further option is that they are argument saturating expressions, which saturate a degree argument. Cf. Kennedy \& McNally (2005b) for a discussion of this matter. For the purposes of this paper this question need not to be resolved (but see the discussion in Fleischhauer 2016 on this point). 


\section{b. viele Bücher \\ much.PL book.PL 'many books' \\ c. viel Wasser \\ much.sG water.sG \\ 'much water'}

Since number is a nominal core operator and viel is sensitive to number, viel has to be located at the core $\mathrm{N}_{\mathrm{N}}$ layer too. The resulting tree for the NP die vielen alten Männer 'the many old men' is shown in figure 4.

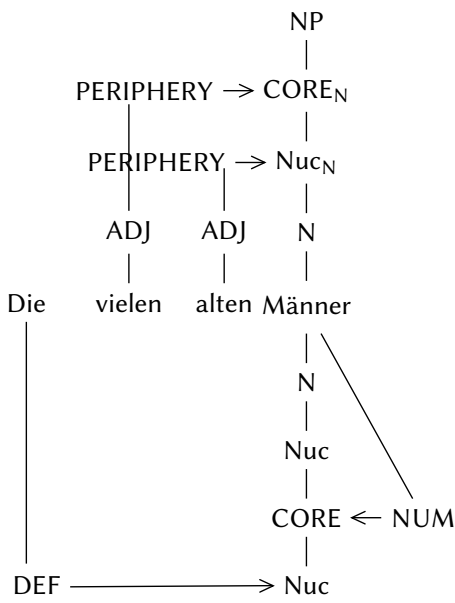

Figure 4: Syntactic structure of the NP die vielen alten Männer.

Analyzing quantity adjectives as located in the periphery of the nominal core fits with Van Valin's characterization of core operators as being about quantity. Ergo, we have the adjectival equivalent to those operators located at the same layer as the operators are. Furthermore, by analyzing viel as a core adjective we receive a uniform syntactic analysis of viel - as located in the core periphery in its adnominal as well as adverbial uses. This leads to the claim that quantity is syntactically realized in the same way across category borders and also makes it possible to explain the cross-linguistic data discussed in section 3. Languages use the same expressions for extent gradation and the specification of a nominal quantity because it is semantically expressed at the core layer. 


\section{Conclusion}

The general topic of this paper was the distinction between verbal extent and degree gradation. It showed that languages mark extent and degree gradation in different ways. Languages such as English and French use the same degree expression for both types of verb gradation, whereas Polish and German (among other languages) have two different degree expressions for both subtypes. The question emerged whether French and English display the same distinction between extent and degree gradation as German and Polish do. The answer given in the paper is: yes, they do. Degree gradation is expressed at the nucleus layer, extent gradation is realized at the core layer. Adverbially used degree expressions such as English $a$ lot and French beaucoup are syntactically ambiguous between core and nucleus adverbs. Corresponding degree expressions in German and Polish are syntactically unambiguous.

A follow-up question is why expressions used for extent gradation can also be used as adnominal quantity expressions, whereas expressions restricted to degree gradation cannot. The answer to this question is that quantity in the nominal domain is also expressed at the core layer. Extent intensifiers operate at the right syntactic layer, which licenses their cross-categorical distribution. This leads to the claim that quantity is uniformly expressed at the core layer, irrespective of whether it is a nominal or verbal quantity.

In a next step, the analysis has to be extended to adadjectival uses of degree expressions like in (40). Van Valin (2008) proposes that also modifier phrases have a layered structure and it would be relevant to how the adjectival data fit into the analysis presented in this paper.

(40) a. Der funge ist sehr groß.

the boy is very tall

'The boy is very tall.'

b. Der funge ist viel größer als sein Bruder. the boy is much taller than his brother 'The boy is much taller than his brother.' 


\section{Acknowledgments}

First of all, I want to thank Robert D. Van Valin for very helpful comments on the topic of this paper and on verb gradation in general. In addition to him, many other people made helpful contributions to this paper: Sebastian Löbner, Thomas Gamerschlag, Adrian Czardybon, Albert Ortmann, Anja Latrouite, Sergej Tatevosov and two anonymous reviewers. I also want to thank my informants Aurélien Jarry, Anselm ter Halle, Patrice Soom, Katina Bontcheva and Syuzan Sachliyan for their help. And finally, I would like to thank the participants of the SFB 991 research colloquium, WoSS 8 in Paris and the 2011 Workshop on Modification in Madrid for their comments on several versions of this paper. The work on this topic is financed by the Deutsche Forschungsgemeinschaft through CRC 991 and is part of project B1 on 'Verb frames at the syntax-semantics interface.'

\section{Appendix}

I.) Data from Tatar (Turkic, Altaic) ${ }^{17}$

Tatar uses two different degree expressions, which are on the one hand bik 'very' for the positive form of adjectives (Ai) and verbal degree gradation (Bi). On the other hand it uses küp 'a lot' for grading comparatives (Aii), verbal extent gradation (Bii, iii) and the expression of adnominal quantity ( $\mathrm{Ci}, \mathrm{ii})$.

(A) i. marat bik bijek.

Marat very tall

'Marat is very tall.'

ii. marat küp-kä alsu-dan bijek-räk.

Marat a lot-DAT Alsu-ABL tall-COMP

'Marat is much taller than Alsu.'

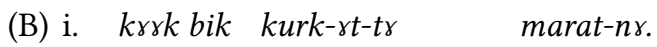

dog very fear-CAUs-PST.3sg Marat-ACC

'The dog frightened Marat a lot.'

ii. marat küp jer-i kino-ga.

Marat a lot go-IPFV cinema-DAT

'Marat goes to the cinema a lot.'

$\overline{17}$ The Tatar data I owe to Sergei Tatevosov. 
Degree Expressions at the Syntax-Semantics Interface

iii. marat küp jrkla-dr kicäge ten-ne.

Marat a lot sleep-PST last night-ACC

'Marat slept a lot last night.'

(C) i. marat küp alma aša-dr.

Marat a lot apple eat-PST

'Marat ate many apples.'

ii. marat küp šurba aša-dr.

Marat a lot soup eat-PST

'Marat ate a lot of soup.'

II.) Data from Bulgarian (Slavic, Indo-European) ${ }^{18}$

Bulgarian uses one and the same degree expression in the adjectival, verbal as well as nominal domain.

(A) a. Momče-to običa mnogo majka si.

boy-DEF loves a lot mother REFL

'The boy loves his mother very much.'

b. Toj hodi mnogo na kino.

he go a lot PREP kino

'He goes to the cinema a lot.'

c. Snošti spah mnogo.

last.night sleep.Aor a lot

'Last night, I slept a lot.' (= long duration)

(B) a. Momče-to e mnogo visoko.

boy-DEF AUX a lot tall

'The boy is very tall.'

b. Momče-to e mnogo po-visoko ot prijatel-ja si.

boy-DEF AUX a lot COMP-tall PREP friend-DEF POSS

'The boy is much taller than his friend.'

(C) a. Toj ima mnogo knigi.

he has a lot book.PL

'He has many books.'

b. V kofa-ta ima mnogo voda.

PREP bucket-DEF has a lot water

'There is much water in the bucket.'

18 The Bulgarian data I owe to Syuzan Sachliyan and Katina Bontcheva. 


\section{References}

Abeille, A., J. Doetjes, A. Molendijk \& H. de Swart. 2004. Adverbs and quantification. In F. Corblin \& H. de Swart (eds.), Handbook of French semantics, 185-209. Stanford: CSLI Publications.

Barwise, J. \& R. Cooper. 1981. Generalized quantifiers and natural language. Linguistics and Philosophy 4: 159-219.

Beavers, J. 2011. On affectedness. Natural Language and Linguistic Theory 29: 335-370.

Bhat, D.N.S. \& R. Pustet. 2000. Adjective. In G. Booji, C. Lehmann \& J. Mugdan (eds.), Morphologie - Ein internationales Handbuch zur Flexion und Wortbildung, 757-769. Berlin/New York: de Gruyter.

Bierwisch, M. 1989. The semantics of gradation. In M. Bierwisch, \& E. Lang (eds.). Dimensional adjectives: Grammatical structure and conceptual interpretation, 71-261. Berlin: Springer.

Bohnemeyer, J. \& R. D. Van Valin, Jr. 2013. The macro-event property and the layered structure of the clause. Manuscript.

Bolinger, D. 1972. Degree words. De Hague: Mouton.

Bosque, I. \& P. Masullo. 1998. On verbal quantification in Spanish. In O. Fullana \& F. Roca (eds.), Studies on the syntax of central Romance languages, 9-63. Gorina: Universitat de Girona.

Cinque, G. 1999. Adverbs and functional heads. Oxford: Oxford University Press.

Comrie, B. 1976. Aspect. Cambridge: Cambridge University Press.

Doetjes, J. 1997. Quantifiers and selection. Dordrecht: Holland Institute of Generative Linguistics.

Doetjes, J. 2007. Adverbs and quantification - degrees versus frequency. Lingua 117: $685-720$.

Dowty, D. 1979. Word meaning and Montague Grammar. Dordrecht: Reidel.

Ebert, K. 2000. Progressive markers in Germanic languages. In Ö. Dahl (ed.), Tense and Aspect in the Languages of Europe, 605-653. Berlin: Mouton de Gruyter.

Esau, H. 1973. Form and function of German adjective endings. Folia Linguistica 6: $136-145$.

Fleischhauer, J. 2013. Interaction of telicity and degree gradation in change of state verbs. In B. Arsenijevi, B. Gehrke \& R. Marín (eds.), Studies in the composition and decomposition of event predicates, 125-152. Dordrecht: Springer. 


\section{References}

Fleischhauer, J. 2016. Degree gradation of verbs. Düsseldorf: düsseldorf university press.

Fleischhauer, J. \& T. Gamerschlag. 2014. We are going through changes: How change of state verbs and arguments combine in scale composition. Lingua 141: 30-47.

Gamerschlag, T. 2014. Stative dimensional verbs in German. Studies in Language 38(2): 275-334.

Gary, E. 1979. Extent in English. University of California, Los Angeles dissertation.

Hay, J., C. Kennedy \& B. Levin. 1999. Scalar Structure Underlies Telicity in "Degree Achievements”. In T. Mathews \& D. Strolovitch (eds.), SALT IX, 127-144. Ithaca: CLC Publications.

Hoeksema, J. 1983. Plurality and conjunction. In A. ter Meulen (ed.), Studies in model-theoretic semantics, 63-83. Dordrecht: Foris.

Jackendoff, R. 1972. Semantic interpretation in generative grammar. Cambridge, MA: The MIT Press.

Karttunen, L. 1975. On the syntax and semantics of the word paljon in Finnish. Acta Linguistica - Congressus Tertius Internationalis Fenno-Ugristarum, 227-235.

Kennedy, C. 1999. Projecting the adjective. New York: Garland.

Kennedy, C. \& L. McNally. 2005. Scale structure, degree modification, and the semantics of gradable predicates. Language 81(2): 345-381.

Klein, E. 1980. A Semantics for positive and comparative adjectives. Linguistics and Philosophy 4: 1-45.

Levin, B. 1993. English verb classes and alternations. Chicago: University of Chicago Press.

Löbner, S. 1987a. Natural language and Generalized Quantifier Theory. In P. Gärdenfors (ed.), Generalized Quantifiers, 181-201. Dordrecht: Reidel.

Löbner, S. 1987b. Quantification as a major module of natural language semantics. In J. Groenendijk, D. de Jongh \& M. Stokhof (eds.), Studies in Discourse Representation Theory and the Theory of Generalized Quantifiers, 53-85. Dordrecht: Foris.

Löbner, S. 1990. Wahr neben falsch. Tübingen: Niemeyer.

Löbner, S. 2002. Is the German Perfekt a perfect Perfect? In I. Kaufmann \& B. Stiebels (eds.), More than words, 369-391. Berlin: Akademie-Verlag. 
Löbner, S. (2012). Sub-compositionality. In M. Werning, W. Hinzen \& E. Machery (eds.), The Oxford Handbook of Compositionality, 220-241. Oxford: Oxford University Press.

Lüpke, F. 2005. A grammar of Falonke argument structure. Radboud Universiteit Nijmegen dissertation.

Maienborn, C. 1996. Situation und Lokation. Die Bedeutung lokaler Adjunkte von Verbalprojektionen. Tübingen: Stauffenburg.

Maienborn, C. 2001. On the position and interpretation of locative modifiers. Natural Language Semantics 9(2): 191-249.

Mora-Bustos, A. 2009. Epistemic adverbs and mood alternation. In L. Guerrero, S. Ibanez Cerda \& V. A. Belloro (eds.), Studies in Role and Reference Grammar, 447-467. México: Universidad Nacional Autónoma de México.

Nuyts, J. 1993. Epistemic modal adverbs and adjectives and the layered representation of conceptual and linguistic structure. Linguistics 31: 933-969.

Ortigosa Pastor, A. 2003. Temporal deictic adverbs - a constructionist approach. Annual Review of Cognitive Linguistics 1: 107-118.

Partee, B. 1988. Many quantifiers. In J. Powers \& K. de Jongh (eds.), Proceedings of the Fifth Eastern States Conference on Linguistics, 383-402. Columbus: The Ohio State University.

Rappaport Hovav, M. 2008. Lexicalized meaning and the internal temporal structure of events. In S. Rothstein (ed.), Theoretical and crosslinguistic approaches to the semantics of aspect, 13-42. Amsterdam/Philadelphia: John Benjamins.

Rappaport Hovav, M. \& B. Levin. 2010. Reflections on manner/result complementarity. In M. Rappaport Hovav, E. Doron \& I. Sichel (eds.), Lexical semantics, syntax, and event structure, 21-38. Oxford: Oxford University Press.

Rice, K. 1989. A grammar of Slave. Berlin: Mouton de Gruyter.

Rice, K. 2000. Morpheme order and semantic scope. Cambridge: Cambridge University Press.

Roberts, J. 1987. Amele. London: Croon Holm.

Sapir, E. 1944. Grading: a study in semantics. Philosophy of Science 11: 93-116.

Solt, S. 2009. The semantics of adjectives of quantity. The City University of New York, New York dissertation.

de Swart, H. 1993. Adverbs of quantification. New York: Garland.

de Swart, H. 1998. Introduction to natural language semantics. Stanford: CSLI Publications. 


\section{References}

Toratani, K. 2007. An RRG analysis of manner adverbial mimetics. Language and Linguistics 8(1): 311-342.

Tsujimura, N. 2001. Degree words and scalar structure in Japanese. Lingua 111: 29-52.

Van Os, C. 1989. Aspekte der Intensivierung im Deutschen. Tübingen: Narr.

Van Valin, R. D., Jr. 2005. Exploring the syntax-semantics interface. Cambridge: Cambridge University Press.

Van Valin, R. D., Jr. 2008. RPs and the nature of lexical and syntactic categories in Role and Reference Grammar. In R. D. Van Valin, Jr. (ed.), Investigations of the syntax-semantics-pragmatics interface, 161-178. Amsterdam: John Benjamins.

Van Valin, R. D., Jr. \& R. LaPolla. 1997. Syntax. Cambridge: Cambridge University Press.

Vecchiato, S. 1999. On the relative order of beaucoup, guère, peu and trop in French. University of Venice Working Papers in Linguistics 9, 255-286.

Vendler, Z. 1957. Verbs and times. The Philosophical Review 66(2): 143-160.

\section{Author}

Jens Fleischhauer

Heinrich-Heine-University Düsseldorf

Department of General Linguistics

fleischhauer@phil.uni-duesseldorf.de 
